
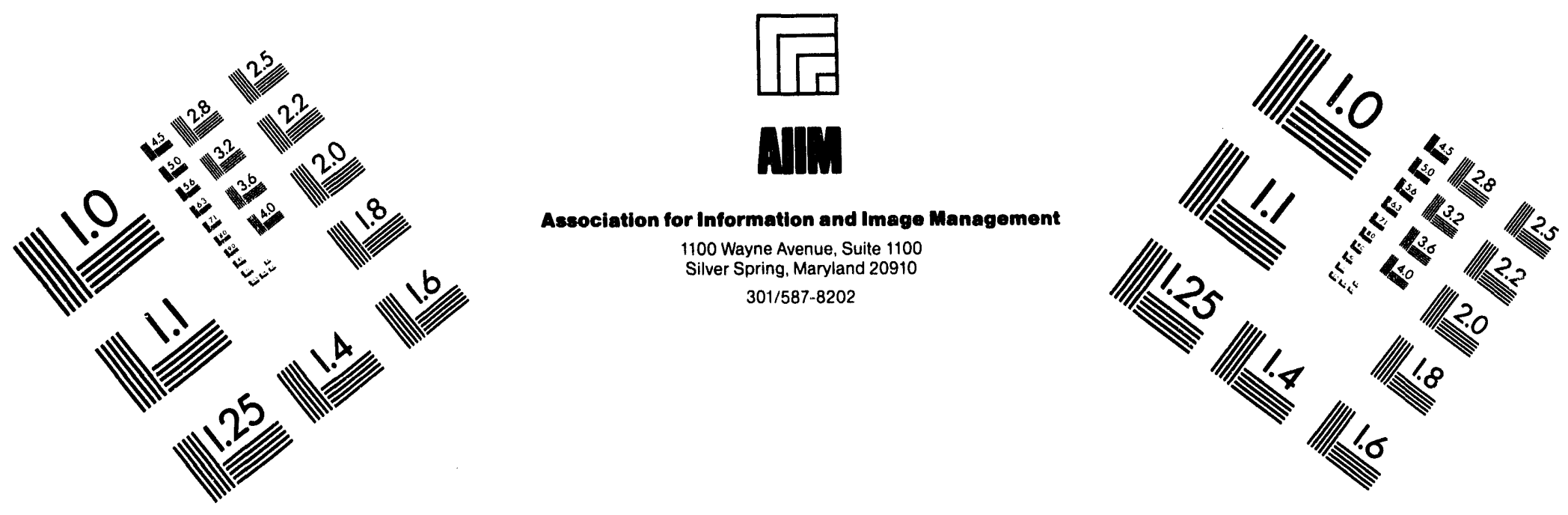

Centimeter

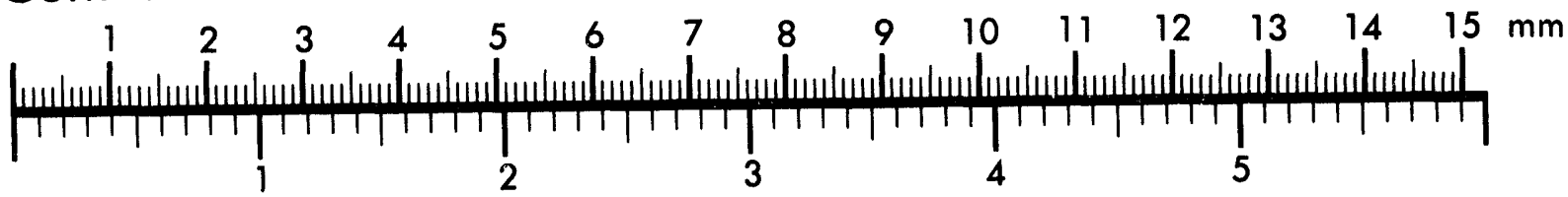
Inches

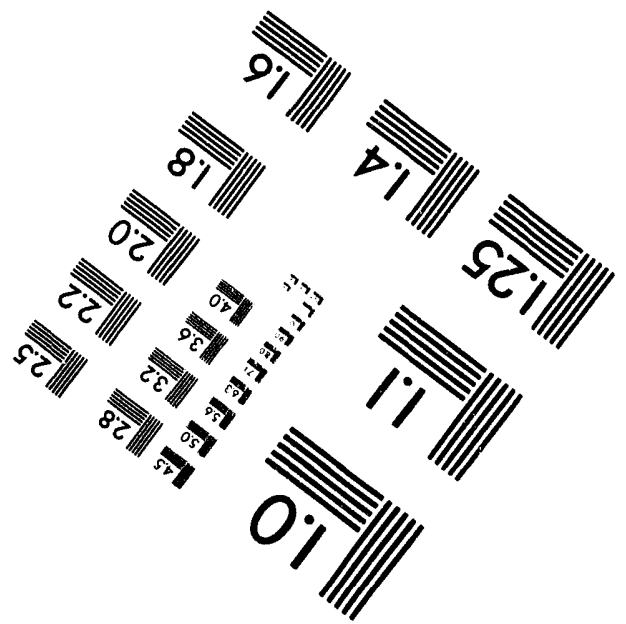

MANUFACTURED TO AIIM STANDARDS

BY APPLIED IMAGE, INC.

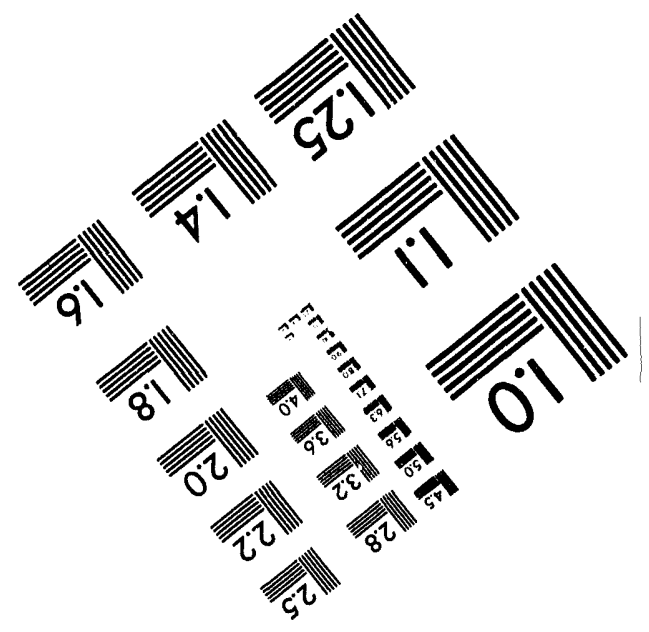



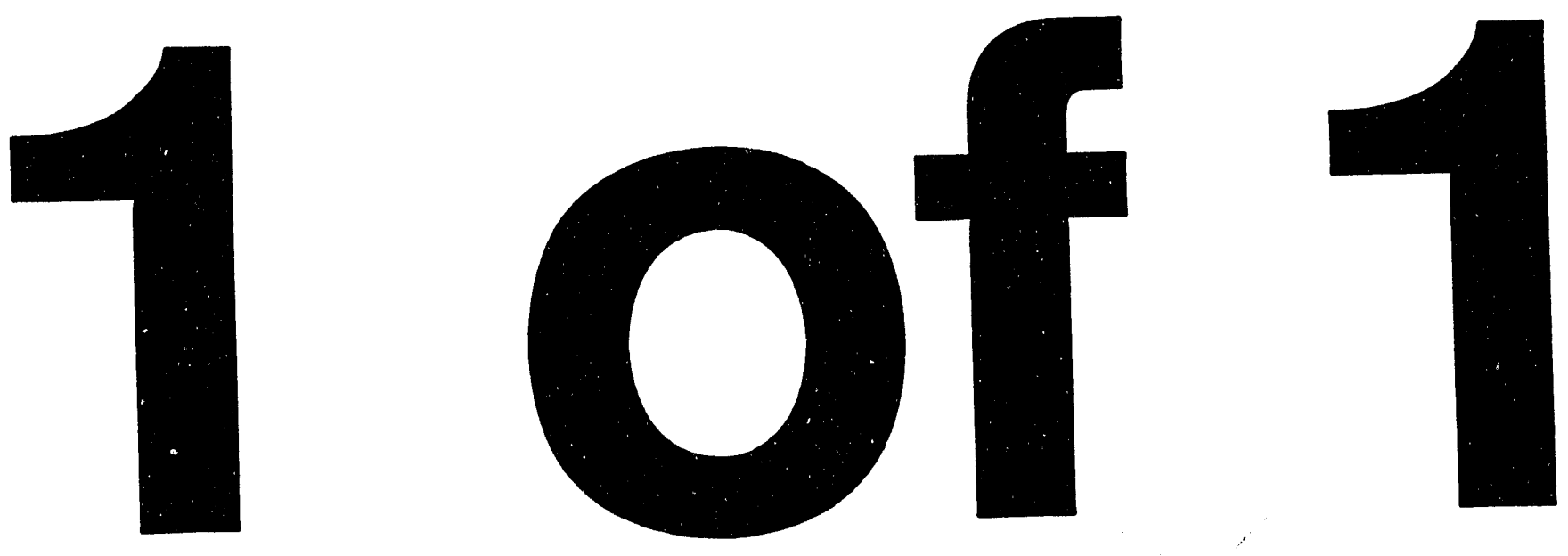


\title{
Advanced, Soluble Hydroliquefaction and Hydrotreating Catalysts
}

Final Report

For the period April 2, 1990 through August 31, 1993

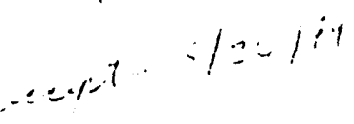

${ }^{\mathrm{a}}$ Richard M. Laine. ${ }^{\mathrm{b}}$ Thomas Stoebe

Feb. 17. 1994

Work Preformed Under Contract No.

DE-FG22-90PC90313

\author{
${ }^{\mathrm{a}}$ Department of Materials Science and Engineering \\ H. H. Dow Building. North Campus \\ Lniversity of Michigan \\ Ann Arbor, MI 48109-2136 \\ ${ }^{b}$ Department of Materials Science and Engineering \\ Roberts Hall. FB-10 \\ University of Washington \\ Seattle, WA 98195
}




\section{DISCLAIMER}

This report was prepared as an account of work sponsored by the United States Government. Neither the United States nor the United States Department of Energy, nor any of their employees, make any warranty, express or implied, or assumes any legal liability or responsibility for the accuracy, completeness, or usefulness of any information, apparatus, product or process disclosed or represents that its use would not infringe privately owned rights. Reference herein to any specific commercial product, process, or service by trade name, mark, manufacturer, or otherwise, does not necessarily constitute or imply its endorsement, recommendation, or favoring by the United States Government or any agency thereof. The views and opinions of authors expressed herein do not necessarily state or reflect those of the United States Government or any agency thereof.

\section{PATENT STATUS}

This technical report is being transmitted in advance of DOE patent clearance and no further dissemination or publication shall be made of the report without prior approval of the DOE Patent Counsel

\section{TECHNICAL STATUS}

This technical report is being transmitted in advance of DOE review and no further dissemination of publication shall be made of the report without prior approval of the DOE Project/Program Manager 


\section{Introduction}

Present efforts to convert coal to fuels by direct hydroliquefaction suffer from being two stage direct processes, requiring high temperatures $\left(>400^{\circ} \mathrm{C}\right)$ and high hydrogen pressures $(\approx 2000 \mathrm{psig})$ to effectively convert coal to a liquid and then to synfuels or petrochemical feedstocks. The need for high $\mathrm{H}_{2}$ pressures results in excessive consumption of $\mathrm{H}_{2}$ and an over-hydrogenated (lower quality) product. For a synfuels from coal process to be economical, all facets of the process must be made as efficient as possible. Improved control of reaction temperatures, $\mathrm{H}_{2}$ pressures and consumption can provide significant improvements in efficiency and economy. All three areas are potentially controllable through careful selection of liquefaction catalysts.

Previous work in this group has shown that, surface confined, organometallic catalysts are exceptionally effective for hydrogenation and HDN of coal model :ompounds such as quinoline. ${ }^{1-6}$ Unfortunately, surface confined catalysts have not proven to be particularly effective when used with coal itself. The problem derives from the fact that: (1) liquefaction is a solid (catalyst)-liquid (coal polymer) reaction system where, (2) diffusion of coal bonds to the heterogeneous catalyst surface is mass transport limited and controls liquefaction rates. Furthermore, heterogeneous catalyst mediated liquefaction is surface area dependent, placing another constraint on reaction rates.

The purpose of the present program is to develop soluble analogs of surface confined catalysts that can be impregnated directly into the coal structure at low temperatures. This approach should avoid problems related to surface area dependence, a two phase (surface-liquid) reaction system and, mass transport limitations.

Heteropolyanions (HPAs) offer the opportunity to develop soluble forms of surface confined catalysts. HPAs, are inexpensive, well-characterized, water soluble metal oxide clusters, e.g. $\left[\mathrm{EM}_{12} \mathrm{O}_{40}\right]^{4-}$ where $\mathrm{E}=\mathrm{Si}$ or $\mathrm{P}$ and $\mathrm{M}=\mathrm{Mo}$ or $\mathrm{W} .^{7}$ They are easily modified to contain other transition metals such as $\mathrm{Co}, \mathrm{Ni}$ or $\mathrm{Ru}$ and, can be made soluble in organic solvents. ${ }^{7-9}$ The protic forms exhibit extremely high acidities $\mathrm{pK}_{\mathrm{a}} \approx 0-2 .{ }^{7}$ In addition, selectively modified HPAs can function as low temperature hydrogenation catalysts that exhibit microporosity. ${ }^{10}$ HPAs are multi-functional catalysts that could be used to promote both hydroliquefaction and hydrotreating. In theory, these functions could be employed sequentially or simultaneously and could permit exceptional control of liquefaction reactions and reaction conditions. Thus, the current research program involves efforts to evaluate HPAs as soluble liquefaction and hydrotreating catalysts, with the goal of developing soluble analogs of surface confined catalysts.

As determined in initial studies, the HPAs act as catalyst precursors rather than catalysts. That is, under useful liquefaction conditions, they decompose to form high surface area bimetallic catalyst particles. The chemical makeup and catalysis behavior of these novel particles was examined with several extremely surprising results. For example (see below), bimetallic CoMo HPAs provided catalyst particles that were no more active (for quinoline hydrogenation) than monometallic Mo catalyst particles. despite the well known fact that CoMo is frequently found to exhibit superior hydrotreating activity when compared to simple Mo based catalysts. The superior behavior is thought to arise because Co provides better hydrogenation activities.

Another surprise was that ruthenium/molybdenum RuMo bimetallic particles were found to exhibit synergistic catalytic behavior for a set of quite different reactions over a wide range of reaction conditions. 
The exploration of the novel properties of these catalyst particles has followed a specific research plan, consisting of three major tasks: (1) Preparation of candidate bimetallic HPA precatalysts; (2) Studies on the decomposition of the precatalyst HPAs to well defined catalyst particles, and (3) studies directed towards delineating the catalytic reactivity patterns of the resulting particles under a set of well defined reaction conditions. The major efforts in each Task are briefly described in the following.

The studies on the preparation, decomposition and catalyst particle characterization are presented in the following chapter which includes the preliminary work published as a Fuel Preprint. Note that we provide an original manuscript and Figures for the preprint as this is of better quality than a photocopy. The catalytic activity patterns for a series of monometallic and bimetallic catalyst particles for quinoline hydrogenation are also described.

\section{Chapter 1.}

a. "Heteropolyanions, Soluble Precatalysts for Quinoline Hydrogenation," S-M. Koo, M.L. Hoppe, Prepr. Am. Chem. Soc. Div. Fuel Chem. (1992) 구, 290-297.

b. "Heteropolyanions as Precursors to Quinoline Hydrogenation Catalysts," S-M. Koo, D. Ryan, G. Huess, R.M. Laine, Energy and Fuels (1993) 7, 981.

Preprints - removed 
Once the particles produced by hydrogenative decomposition of ethanol soluble, polyoxoanions, heteropolyoxoanions and bimetallic heteropolyoxoanions were physically characterized and their quinoline hydrogenation reactivity patterns determined; the next step was to examine THQ reactions at higher temperatures. Because the decomposition and $\mathbf{Q}$ hydrogenation reactions were studied primarily in $\mathrm{EtOH}$, it was assumed that in higher temperature studies, the fresh catalyst particles would be generated in situ at the higher reaction temperatures; however, these studies demonstrated that the surface areas produced at higher temperatures were lower than obtained at the original $170^{\circ} \mathrm{C}$ decomposition temperatures. Because our objective is to generate highly active catalysts, it was decided that $170^{\circ} \mathrm{C}, \mathrm{EtOH}$ generated catalyst particles would be the benchmark catalysts.

The first goal was to seek the lowest temperature where THQ could be observed to react, as an approach to identifying the most promising catalysts for future development. Thus, initial studies examined THQ reactivity at temperatures ranging from $200-250^{\circ} \mathrm{C}$. The results of these studies were quite surprising. Rather than effect THQ HDN it was observed that all of the catalysts promoted $\mathrm{N}$-ethylation of THQ. Furthermore, the RuMo catalysts were again found to offer the most active systems pointing to novel and wider scope synergistic effects. The details of these studies are presented in Chapter 2 of this report, which follows. Chapter 2 again contains the preliminary work, which was described in a Fuel Division Preprint, and then a full paper, published in J. Appl. Organometallic Chemistry.

\section{Chapter 2.}

a. "Ethylation of Tetrahydroquinoline Using Ru/Mo Bimetallic Catalyst Precursors," S-M. Koo, D.Ryan, R.M. Laine, Prepr. Am. Chem. Soc. Div. Fuel Chemistry (1992) $\underline{37}, 275-282$.

b. "Sulfided Heterogeneous, Bimetallic RuMo Catalysts Derived from Mixtures of $\mathrm{Ru}_{3}(\mathrm{CO})_{12}$ (or $\mathrm{RuCl}_{3}$ ) and $\mathrm{H}_{3} \mathrm{PMo}_{12} \mathrm{O}_{40}$. Reactions of EtOH with THQ," S-M. Koo, D. Ryan, R.M. Laine, Appl. Organomet. Chem. 6,437-448 (1992). 
The observation of Mo, RuMo and Ru catalyzed ethylation of THQ made it obvious that true studies of THQ HDN could not be run in EtOH. Consequently, a decision was made to prepare larger quantities of catalysts ex-situ in EtOH, characterize these catalysts, and then perform THQ HDN studies in hexadecane solvent, a solvent we had previously used for our supported catalyst studies. This method proved to work quite well. We now report studies on the use of hexadecane solvent with undecane or decane as the GC standard. The catalysts used are the same as prepared in bulk quantities for the ethylation studies. The following studies were run using a $\mathrm{MoS}_{x}$ catalyst with a BET determined surface area of $7.3 \mathrm{~m}^{2} / \mathrm{g}$. Likewise, the RuMoS $x$ catalyst was found to have a specific surface area (SSA) of $3.5 \mathrm{~m}^{2} / \mathrm{g}$. Preliminary comparitive studies were performed with a RuS $_{x}$ with a SSA of $\approx 17 \mathrm{~m}^{2} / \mathrm{g}$.

\section{Experimental}

These reaction conditions typically involved the addition of a known amount of THQ, propylaniline, or propylbenezene to a hexadecane solution containing a known amount of decane or undecane as an internal standard for GC analysis.

For example, RuMo catalyst particles with 1:11 Ru:Mo, generated under conditions identical to the $\mathrm{Q}$ hydrogenation reactions, at $175^{\circ} \mathrm{C}$, but in the absence of $\mathrm{Q}$, as noted in chapter 1 were used. Studies were done with two $250 \mathrm{mg}$ batches of catalyst which were mixed to obtain a uniform catalyst.

Product analyses for all the kinetic studies were performed on a temperature programmed HewlettPackard 5890A reporting GC equipped with FID using a $12 \mathrm{~m} \mathrm{x} 0.53 \mathrm{~mm} \times 2.65 \mu \mathrm{m}$ capillary column packed with $100 \%$ dimethyl polysiloxane gum. The column heating schedule was initiated with a hold at $35^{\circ} \mathrm{C}\left(4 \mathrm{~min}\right.$ ) followed by ramping at $5^{\circ} \mathrm{C} / \mathrm{min}$ to $100^{\circ} \mathrm{C}$ and then at $40^{\circ} \mathrm{C} / \mathrm{min}$ to $250^{\circ} \mathrm{C}$. The eluting gas mixture was $\mathrm{H}_{2} / \mathrm{He}$.

GC-MS studies were performed using an HP 5890 Series II GC, an HP 5970 mass spectrometer, and the HP 5940 MS Chemstation. The capillary column used for product separation was a $12 \mathrm{~m} \mathrm{x} 0.12 \mathrm{~mm} \mathrm{x}$ $0.33 \mu \mathrm{m}$ film thickness HP-5 (crosslinked 5\% phenyl methyl silicone) capillary column. The temperature for the analysis was held at $50^{\circ} \mathrm{C}$ for $5 \mathrm{~min}$, then ramped at $4^{\circ} \mathrm{C} / \mathrm{min}$ to $275^{\circ} \mathrm{C}$. The eluting gas used was $\mathrm{H}_{2} / \mathrm{He}$.

\section{THQ HDN Kinetic Runs}

Typically, $18-20 \mathrm{mg}$ of catalyst are added to a solution of $1.0 \mathrm{ml}(8.5 \mathrm{mmol})$ of THQ (or $\mathrm{mmol}$ equivalents of PA, or P B) mixed with $9.0 \mathrm{ml}$ of hexadecane and $50 \mu \mathrm{l}$ of decane as internal standard in a quartz lined, Parr General Purpose Bomb reactor with a $34 \mathrm{ml}$ internal volume. The reaction solution is then pressurized to $400 \mathrm{psig}$ with $\mathrm{N}_{2}$ at RT and depressurized. The process is repeated and then $400 \mathrm{psig}$ with $\mathrm{H}_{2}$ at $\mathrm{RT}$ is added and the reaction is heated, with magnetic stirring, to the $370^{\circ} \mathrm{C}$ for the studies shown below. At the appropriate times (typically $0,10,20,30,60$ and $300 \mathrm{~min}$ ) the reactor is cooled in flowing water, depressurized and a sample is taken for $\mathrm{GC}$ analysis. The reactions are run to less than $25 \%$ conversion so that the initial rates of product formation correspond essentially to zero order in reactant concentration. Note that the reaction times used here are much shorter than used at lower temperatures as the rates of reaction are relatively high.

The work reported in the following pages was fraught with analytical problems that required 4 months to resolve and were a consequence of a distorted gold leaf disc located (hidden) in the GC injection system that led to irreproducible results. Hewlett Packard was able to fix this problem but only after a significant 
effort was made in-house to troubleshoot the problem.

THQ HDN produces a wide variety of primary, secondary and tertiary products including decahydroquinoline, propylaniline, propylbenzene, propylcyclohexene, and propylcyclohexane as shown in the following HDN network:

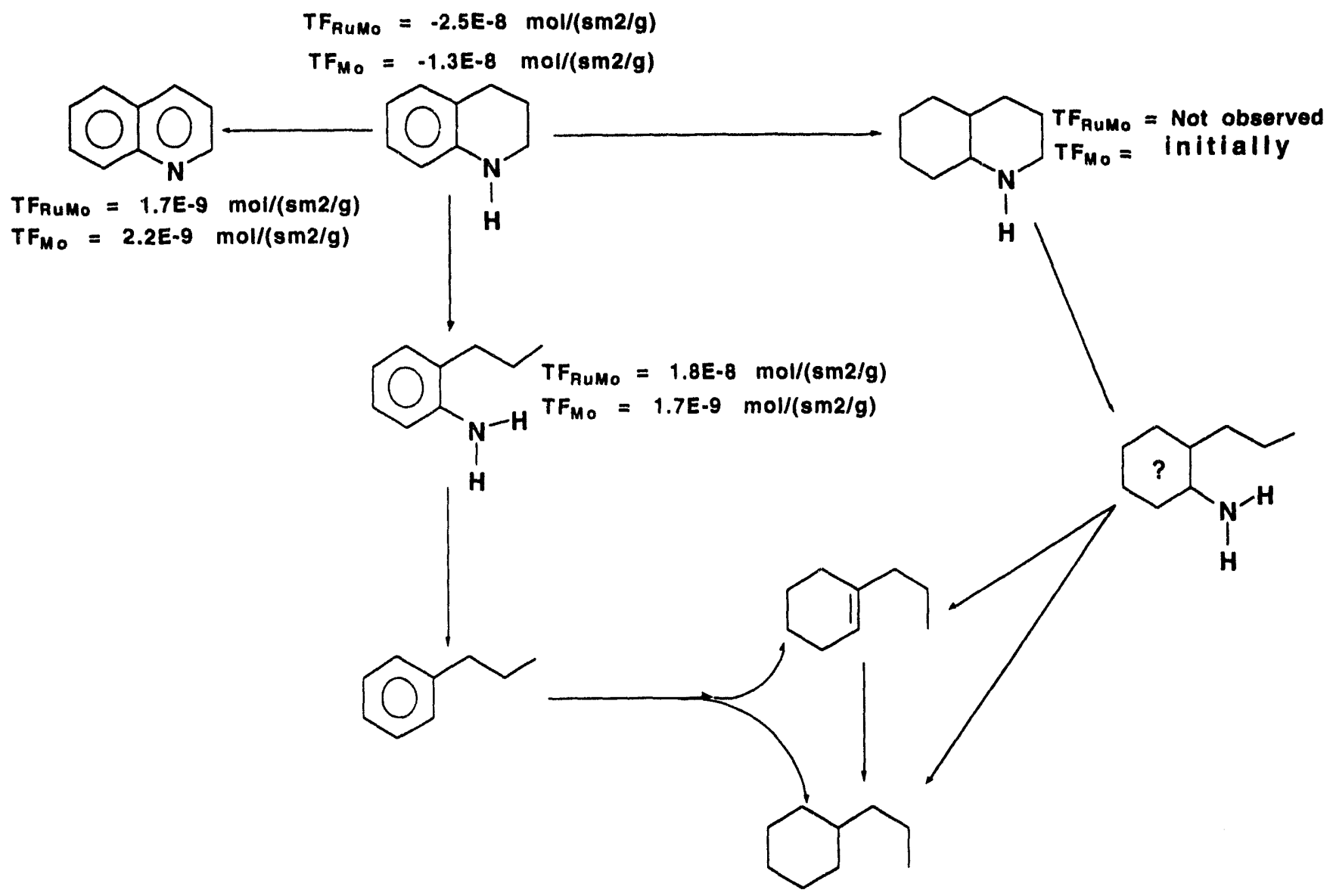

To best characterize the catalytic reactivity patterns of each type of catalyst with each component of the reaction network, we sought to examine the reactivities of the individual catalysts with selected components of the above reaction network. Thus, we examined the reactivities of the RuMo and Mo sulfided catalysts for: (1) HDN of THQ, (2) propylaniline-PA, and (3) propylbenzene--P B.

In general, the reactivity of the RuMo catalyst for effecting specific types of reactions was higher than that found for the Mo catalyst. Initial studies with the Ru catalyst alone suggest that it has relatively lower reactivities than either the RuMo or Mo catalysts. A more complete study can only be completed after this final report has been submitted.

The exact reactivities for each catalyst were determined by selecting individual components of the above THQ HDN reaction network to determine their particular reactivity patterns with the two types of catalysts. In the following sections, we present some of our primary findings about product disappearence rates and formation rates [as TFs $=($ moles reacted or formed $)\left(\mathrm{sec} \cdot \mathrm{m}^{2} / \mathrm{g}\right)^{-1}$ ] for disappearence and appearence for selected products as shown in the series of schematics.

We are particularly interest in the reactivity pattern of propylbenzene as it (1) represents aromatics in coal liquefaction, (2) is a sink for hydrogen and (3) thereby controls to some extent $\mathrm{H}_{2}$ consumption during hydrotreating: 


\section{Propylbenzene Hydrogenation}

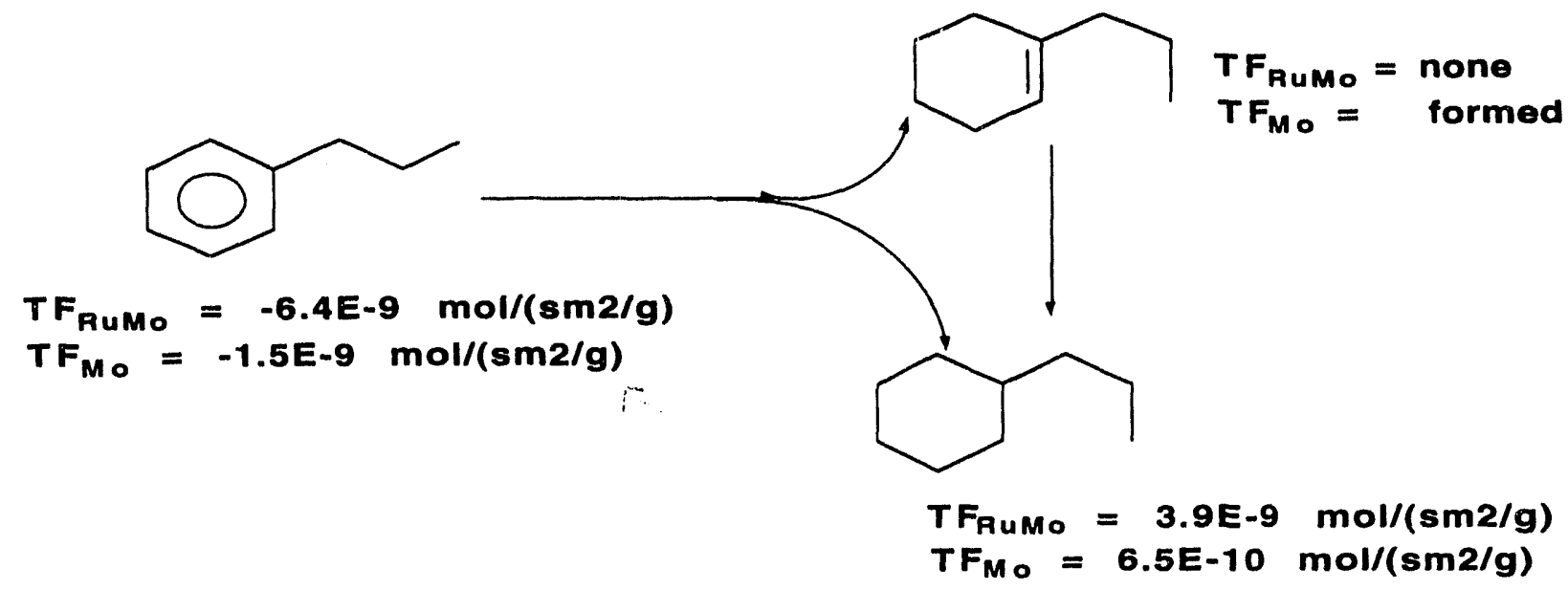

Note that this study is incomplete in part because of the problems.with the GC and in part because only one undergraduate has been working on the project part-time.

The primary observation is that $\mathbf{P B}$ hydrogenation by both catalysts $(\mathrm{TFs}=-6.4 \mathrm{x}$ and $1.5 \mathrm{E}-9$ for RuMo and Mo respectively) are comparable to the PB appearance rates found during PA HDN as shown in the following network fragment:

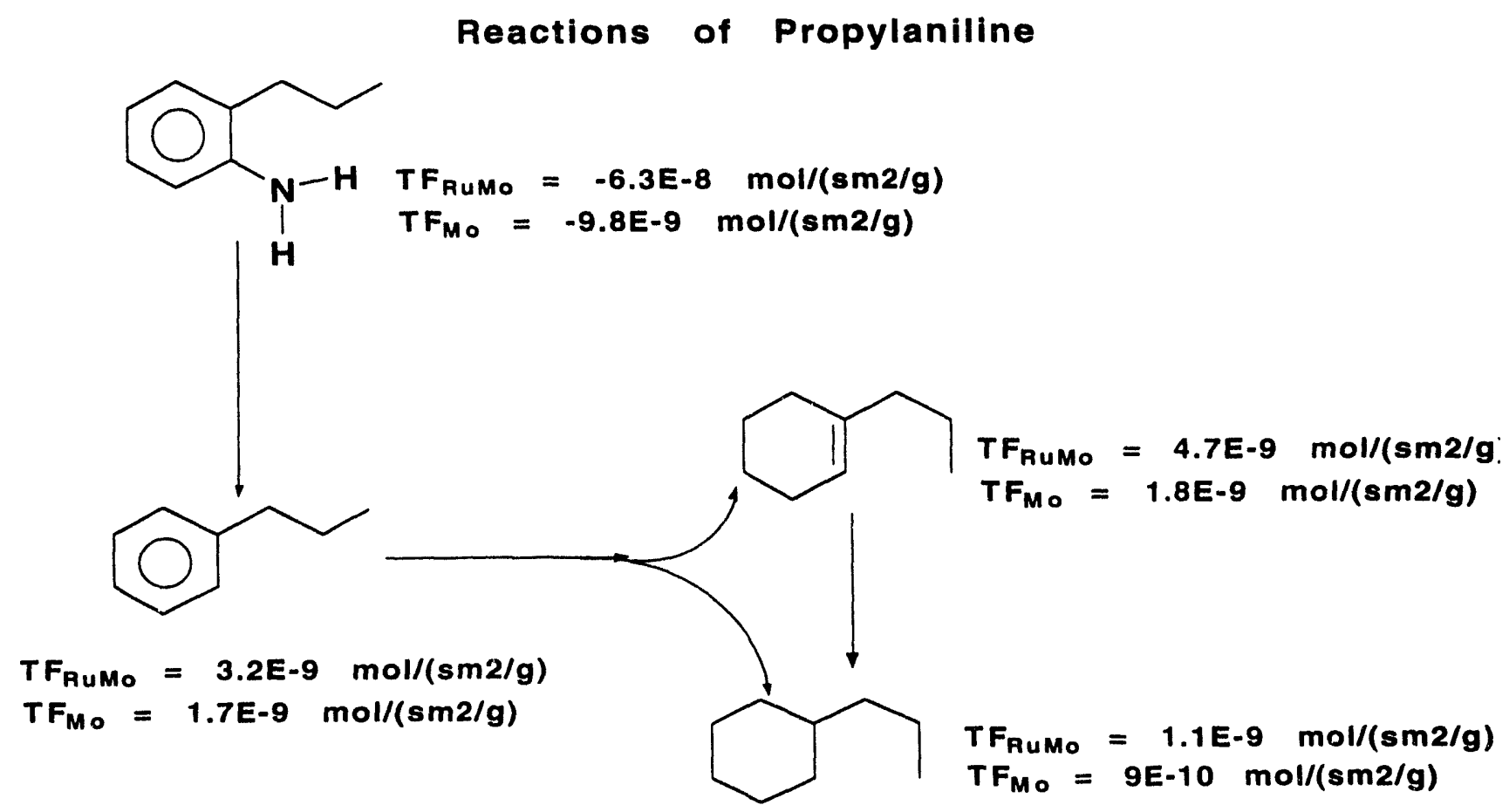

Recall that these appearence rates are still concentration dependent and the disappearance rates measured are for relatively high concentrations by comparison with quantities of $\mathbf{P B}$, that will from during PA and THQ HDN. Thus, we do not need to consider them in discussions that concern the reactivity profiles of the various products formed in these last two processes. 
In the PA HDN studies the primary products formed are those commonly observed, PB, PC (propylcyclohexene) and PCH (propylcyclohexane). The RuMo catalyst exhibits slightly less than $2 \mathrm{x}$ the activity of the Mo catalyst for HDN of PA, as might be predicted based on the lower temperature Chapters 1 and 2 studies. The PB:PC:PCH product selectivities for both catalysts are:

\begin{tabular}{|c|c|c|c|}
\hline$\underline{\text { RuMo }}$ & PB:PC:PCH & $=$ & $3.2: 4.7: 1.1$ \\
\hline$\underline{\text { Mo }}$ & PB:PC:PCH & $=$ & $\begin{array}{r}1.7: 1.8: 0.9 \\
.4\end{array}$ \\
\hline
\end{tabular}

These results are quite interesting for two reasons, the product selectivities are nearly identical, however, the RuMo rates are $\approx 6$ times higher based on PA disappearence and 2 times higher based on rates of product appearence; however, we have not included several minor products in detailing the product selectivity pattern. We conclude that the rate differences are real.

We have also begun to examine the complete THQ HDN process and find that (see complete HDN network above) THQ rates of disappearance for RuMo (2.5xE-8) and Mo (1.3x E-8) are 50\% higher than the rates of product appearence. The selectivities to two of the expected products, $\mathbf{Q}$ and $\mathbf{P A}$, are 15:1 for RuMo and 5.5:1 RuMo respectively, these are what might be expected based on the similarity in the PA studies. These will have to be examined in more depth at a later date.

Recall that both catalyst systems use approximately the same amount of metal, but the RuMo system replaces $0.08 \%$ of the total Mo with some $\mathrm{Ru}$. Thus, there appears to be an increase in reactivity obtained by including $\mathrm{Ru}$ in the system. This is still better than expected based on Ru baseline studies presented in our recent Fuel Preprint--see Chapter 3, below.

The obvious general conclusion that can be made is that like all of the other reactions studied, the RuMo catalyst exhibits more activity than a simple Ru or Mo catalyst made from essentially the same starting materials. This points to a rather broad synergistic behavior for this bimetallic catalyst. At this time, it is not possible to delineate all of the important features of the RuMo sulfided catalyst; however, in the opinion of this research group, there is much to be learned through continued exploration of this catalyst system for HDN, HDS and HDO.

We thank the DOE/PETC for generous support and patience during the performance of this work.

A portion of the above work was published as Chapter 3 .

3. "Bimetallic Ru/Mo Catalyst Particles for HDN of Tetrahydroquinoline," D.B. Ryan, T. Hinklin, G. Heuss, S.-M. Koo, R.M. Laine, Prepr. Am. Chem. Soc. Div. Fuel Chemistry, (1993) 38, 542-545. 

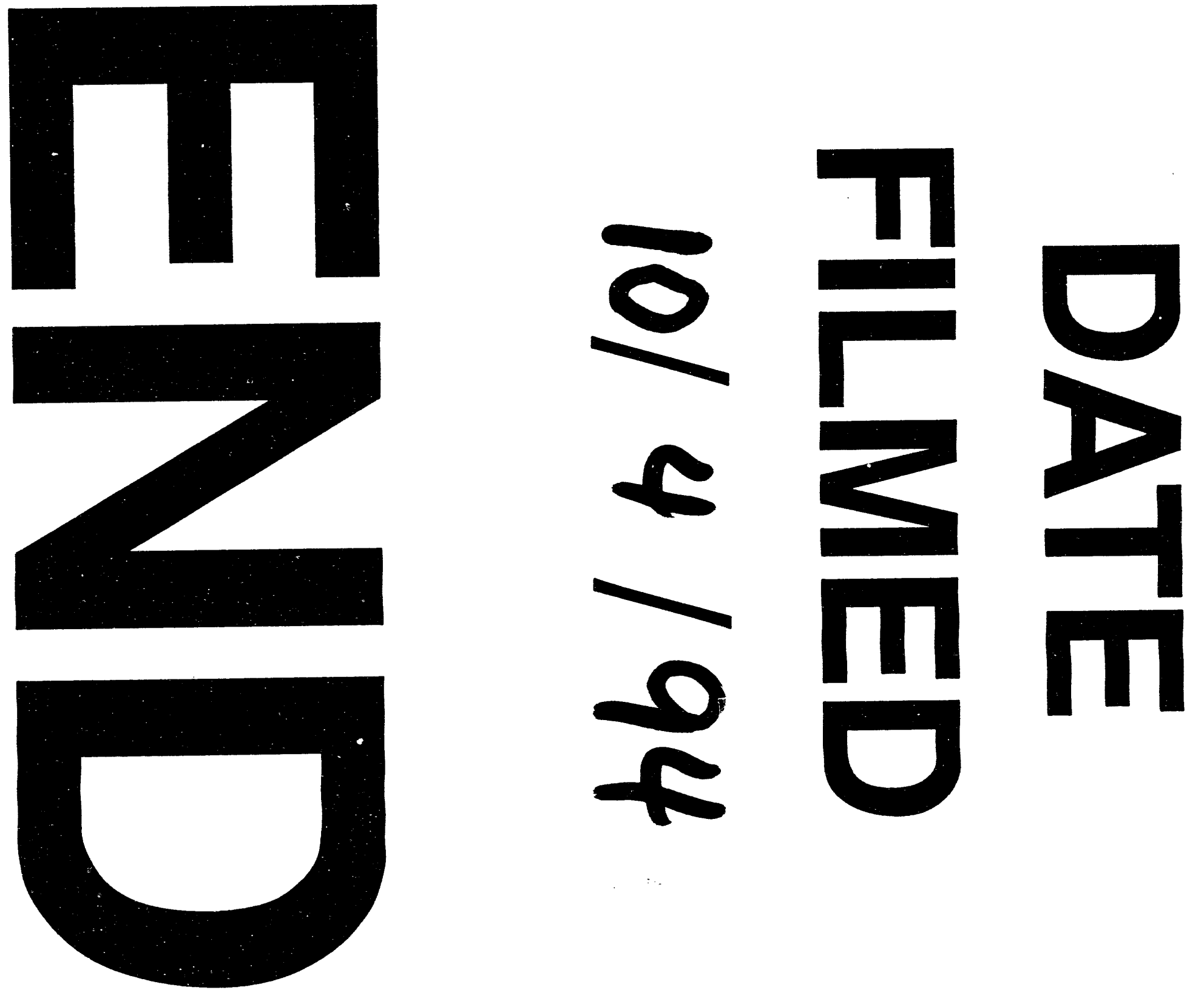
